\title{
Organic Vegetable Production and How It Relates to LISA
}

\author{
Vernon P. Grubinger \\ University of Vermont Extension System, P.O. Box 2430, West Brattleboro, VT 05303-2430
}

\begin{abstract}
Organic farming and the Low Input Sustainable Agriculture (LISA) program are both part of an alternative agricultural movement that promotes the use of biological interactions and cultural practices over agricultural chemicals. The goal of this movement is productive, profitable agriculture that protects the natural resources that are essential to long-term sustainability.

While there are many production practices that are accepted as both organic and LISA, these terms are not synonymous. The use of synthetic pesticides and fertilizers is largely prohibited on organic farms but allowed to some extent by LISA. In addition, certification programs have been developed for organic farms but not for LISA practitioners.
\end{abstract}

\section{Definitions}

LISA. The U.S. Dept. of Agriculture initiated the LISA research and education grants program in 1988 as part of the 1985 Food Security Act. The term LISA is frequently used to describe the recently changed way in which mainstream farmers and researchers approach agricultural problem-solving. This change is based largely on an increasing awareness that farm practices must be judged not only by their effect on short-term yield and profit but also by their impact on water quality, soil productivity, and human health. These concerns have come to the forefront in the so-called conventional agricultural community largely since LISA's inception and partially as a result of the credibility that LISA has lent to alternative agricultural practices intended to address such concerns.

LISA is meant to "lessen the farmer's dependence on purchased inputs, especially synthetic chemical pesticides and fertilizers...(by) greater use of crop rotations, crop and livestock diversification, soil and water conservation practices, greater use of animal and green manures, biological pest controls, and mechanical cultivation where appropriate" (U.S. Dept. of Agr. 1991). It is generally acknowledged that technologies that reduce the need for purchased inputs depend on greater inputs of information and management; thus, the term lowinput is somewhat misleading. The recent report on alternative agriculture by the National Research Council, which describes farms that use many LISA practices, concludes that alternative farming is not based on a well-defined set of management techniques but on a range of technologies and management options (National Res. Council, 1989).

Organic. Many of the alternative practices promoted by LISA are also those that are frequently found on organic farms. However, the use of synthetic nutrients and pesticides is largely avoided by organic producers, while LISA allows the wise and limited use of such inputs. Therefore, organic practices comprise a subset of those promoted by LISA.

Organic farming was defined by the landmark U.S. Dept. of Agriculture report of 1980 as "...production systems which avoid or largely exclude the use of synthetically compounded fertilizers, pesticides, growth regulators and...rely upon crop rotations, crop residues, animal manures, green manures, off-farm organic wastes, mechanical cultivation, mineral bearing rocks, and aspects of biological pest control to maintain soil productivity and tilth, to supply plant nutrients, and to control insects, weeds, and other pests" (U.S. Dept. of Agr., 1980).

Over the last decade, clearly defined standards for organic farm certification have been developed in many states. With a few exceptions, certification programs for organic foods are based on production standards, rather than on residue tests or other food quality standards. This may in part be true because claims that organic food is superior in taste or safety have not been substantiated, while the agronomic benefits of organic farming practices are well documented (Inst. of Food Technologists, 1990). Not only do certification programs provide specific written information about how organic food has been produced, but they also assure compliance with the standards through documentation of inputs and yearly farm inspections. Lists of permitted and prohibited inputs, including specific commercial brands, are published in the certification handbooks of some states (Natural Organic Farmers Assn. of N.Y., 1991; California Certified Organic Farmers Certification Handbook, 1990). Certification programs are currently administered by private grower organizations, state departments of agriculture, or a combination of the two (Grubinger, 1991).

The recently formulated federal definition of organic, scheduled to supersede all others in 1993, specifies that food labeled as organic "...shall have been produced without the use of synthetic chemicals.. .not...on land to which prohibited substances, including synthetic chemicals have been applied during the 3 years immediately preceding the harvest...in compliance with an organic plan.. ." (Congressional Record, 1990). Exceptions to the ban on synthetic inputs may include: copper and sulfur compounds, bacterial toxins, pheromones, soaps, oils, treated seed, vitamins and minerals, netting, wraps and seals, insect traps, row covers, mulches, and equipment cleansers. Under the federal guidelines, a national organic standards board will be created to assist the U.S. Dept. of Agriculture in developing a national list of approved organic inputs.

Because there are strict limitations on synthetic inputs that may be used under organic standards, there is a strong incentive for organic vegetable growers to make extensive use of nonchemical practices that are fundamental to LISA. Indeed, to maintain a successful organic system requires the adoption and integration of a majority of the individual LISA techniques mentioned above.

While organic farming differs from the LISA concept with regard to extent of synthetic input use and the availability of certification programs, it shares a systems approach to crop management, and an emphasis on making the best use of biological resources.

\section{Organic vegetable production practices}

To succeed, organic vegetable growers vigorously pursue nonchemical production practices. Their approach is often innovative and sometimes unorthodox, but in the view of some, they are braving a new frontier by taking risks with new production techniques that other growers are not inclined to take. Rather than reducing their use of synthetic inputs, which is the thrust of programs such as integrated pest management (IPM), organic farmers have ventured into uncharted waters, abandoning many of the chemical "tools" widely deemed essential for vegetable production. Ironically, there is mutual agreement among organic farmers and agricultural researchers that organic approaches to pest control and nutrient management have not been sufficiently studied. Organic farmers claim that the research establishment does not serve them, and researchers dismiss many organic practices as unsubstantiated. I hope that such criticism will be mitigated by the fact that organic farms are often used by LISA 
researchers as a setting for studying alternative methods of crop production.

When comparing organic and nonorganic farming, it is important to recognize that management skills vary within any group of farmers. Just as there are conventional growers that do an excellent job of resource protection and soil husbandry, so, too, are there organic farmers who contribute to environmental degradation. However, wellrun organic farms present a useful model for study because they effectively use LISA strategies to minimize many of the problems that have become all-too commonplace on conventional, chemical-intensive farms.

Crop rotation. Successful organic vegetable production is not possible over the long term unless intensive crop rotation is practiced. Without the use of synthetic pesticides, prevention of insect, disease, and weed proliferation through crop rotation becomes essential. Although organically approved pesticides are widely available, they are generally more expensive and less effective than their synthetic counterparts, so a simple substitutive approach to organic pest management is not economically viable.

Rotation has long been touted as a good management practice, and it is widely practiced by many conventional producers, at least among a few crops. The good managers of organic farms have simply taken this concept a step further, diversifying their crop mix sufficiently so as to have many years of rotation before a given family of crop is replanted in a particular field. In addition, such managers have found ways to include sod crops in their rotation to provide a respite from row-crop cultivation. This practice is usually economically feasible only when livestock are produced on or near the farm so that the sod crop can be used as hay.

Weed control. Weed control is one of the biggest obstacles to organic vegetable production. With most crops, some hand-weeding is necessary to avoid yield reductions, but because excessive weed growth or hand-weeding are expensive options, mechanized weed control is extensive on organic vegetable farms. Growers use a variety of cultivation implements, such as basket and finger weeders, rakes, rolling cultivators, disks, tines, sweeps, and innovative combinations thereof. Mulches, flame weeding, and stale seedbeds are also used to manage weeds. A smother crop rotation such as two buckwheat crops followed by rye is sometimes used in fields with heavy weed pressure.

Insect control. The use of classical biological control is practiced on some organic farms through the purchase and release of pest predators and parasites. However, relatively few growers are using this approach on a large scale. Conservation of indigenous predators and parasites is more common, albeit sometimes unintentional, by the avoidance of broad-spectrum insecticides.

The use of microbial insecticides, especially the Bacillus thuringensis type, is widespread on organic vegetable farms. There is a variety of commercial formulations, and growers have become familiar with how to best use them. Microbial insecticides offer an attractive alternative to botanical insecticides, many of which are broad spectrum in activity and rather toxic. Some organic growers are following a formal IPM program, using traps and scouting to optimize their use of organically approved insecticides.

Row covers are frequently used to exclude insects from organic crops, particularly during the early stages of plant development. To manage pests that overwinter in the soil, crop rotation must be used in conjunctionwith this technique. Crop vacuums are another mechanical means of insect control, but they are not widely used at this time.

Disease management. Organic growers largely depend on cultural practices and resistant varieties to avoid disease problems. Sulfur and copper compounds are permitted under most organic standards, but their efficacy is less than that of many synthetics, except on a few plant diseases. Additionally, the sustainability of repeated application of these materials is questionable. Crop rotation is the key to organic disease management, in conjunction with proper sanitation, stress avoidance and microclimate modification via crop spacing, raised beds, and well-timed irrigation.

Plant nutrition. Organic residues are the primary source of plant nutrients on organic farms. As opposed to using the conventional approach, which generally views organic residues as a supplement to other fertilizers, organic farmers add fertilizers only when residues alone cannot meet the nutrient needs of their crops. This may be the case in soils that are chronically low in a nutrient, early in the season when soils are cool and mineralization rates are low, or during transition to an organicsystem before the cumulative effects of residue additions over several years have been realized.

The use of low rates of some synthetic fertilizers is considered by many to be a sustainable practice, and the organic prohibition of this practice can be difficult to justify on an agronomic basis, particularly with regard to the ban on acidulated phosphates (Parnes, 1990). Many growers who consider themselves to be organic would not qualify for certification due to their limited use of synthetic fertilizers. This is a particularly controversial issue with regard to greenhouse production of transplants.

Organic matter maintenance. Soil husbandry is of the utmost importance to most organic vegetable producers. Where animal manures are available, they are obtained in large quantities, often at considerable expense. In many cases, other types of organic residues are imported to the farm, composted, then added to the soil. Residues such as apple pomace, lake weeds, domestic yard wastes, and brewery, slaughterhouse, and other food processing wastes are examples of locally available wastes that are used to make compost. The quality of compost produced on organic farmsvaries considerably. Where growers are making their own compost-based mixes for greenhouse seedling production, the quality of the compost must be quite high.

Green manures are commonplace on organic farms as winter cover crops, summer catch crops, and rotational crops. The addition of hairy vetch to a traditional winter rye cover crop, a practice studied and promoted by a LISA project, has become popular among organic vegetable growers looking for the extra $\mathrm{N}$ that the vetch can provide. In general, organic vegetable growers are eager to experiment with new cover crop species and management strategies.

\section{Conclusion}

Organic growers use many LISA techniques, and are for the most part keenly interested in the interactions among their cropping practices and the long-term impact that they are having on the land. It is this type of holistic approach to farming that unites organic growers and LISA proponents in their efforts to be sustainable. With that in mind, a greater effort should be made to foster communication between organic vegetable growers and progressive conventional producers looking for ways to reduce their use of synthetic inputs and protect the quality of their soil and water.

\section{Literature Cited}

California Certified Organic Farmers Certification Handbook. 1990. CCOF, Inc., Santa Cruz, Calif.

Congressional Record. 1990. Public Law 101-624, 28 Nov. 1990. Food, Agriculture, Conservation and Trade Act of 1990. Title XXI, Organic Certification. Congr. Record S.10959, Washington, D.C.

Grubinger, V.P. Organic certification, a primer. Proc. 1991 Ill. Specialty Growers Convention, Univ. of Illinois, Urbana.

Institute of Food Technologists. 1990. Organically grown foods. Food Technol. 12:123.

National Research Council, 1989. Alternative agriculture. Natl. Acad. Sci., National Press, Washington, D.C.

Natural Organic Farmers Assn. of New York. 1991. Organic farm certification program standards and administrative rules. NOFANY, Ithaca.

Parnes, R. 1990. Fertile soil: Agrower's guide to organic and inorganic fertilizers. AgAcess, Davis, Calif.

U.S. Department of Agriculture. 1980. Report and recommendations on organic farming. U.S. Dept. Agr., Study Team on Organic Farming, Washington, D.C.

U.S. Department of Agriculture. 1991. Guidelines for grants programs on sustainable agriculture. CSRS, U.S. Dept. Agr., Washington, D.C. 